\title{
Cesarean Section: A Storm in a Cup???
}

\author{
${ }^{1}$ Niranjan Shah, ${ }^{2}$ Narendra Malhotra, ${ }^{3}$ Jaideep Malhotra, ${ }^{4}$ Ruchika Garg, ${ }^{5}$ Jaydeep Tank, ${ }^{6}$ Neharika Malhotra
}

How to cite this article: Shah N, Malhotra N, Malhotra J, Garg R, Tank J, Malhotra N.. Cesarean Section: A Storm in a Cup??? J South Asian Feder Obst Gynae 2017;9(4):291-296.

Source of support: Nil

Conflict of interest: None

Date of received: 5 October 2017

Date of acceptance: 10 November 2017

Date of publication: January 2018

\section{INTRODUCTION}

The issue of rising rates of C-sections (CSs) in India has been further brought into the limelight by a petition on Change.org by Subarna Ghosh, addressed to the Union Minister for Women and Child Development, Maneka Gandhi. The petition asks the government to direct hospitals to be more transparent about the percentage of CSs they conduct. The government has taken cognizance of the petition, indicating that the matter may be tabled for deliberations and future course of guidelines. However, to curb the epidemic of unnecessary CSs in India, standard operating procedures may be suggested to be developed and implemented, which may attempt to lay down the scientific criteria for such operations. Whether that task is possible or not is left to everyone's speculation, and so also if it was sufficient or possible to lay down guidelines and laws in such a situation hastily? Furthermore, should the entire scenario be reassessed as it is not sufficient to simply issue out poorly thought-out guidelines? The issue needs to be looked at broadly with the involvement of a cross-section of stakeholders.

All the factors that have been blamed to have propelled the cesarean rates, such as changes in lifestyle, psychosomatic disability of women to handle vaginal

\footnotetext{
1-3,5,6 Consultant, ${ }^{4}$ Associate Professor

${ }^{1}$ Department of Obstetrics and Gynecology, Lotus Hospital \& Research Centre, Kolhapur, Maharashtra, India

${ }^{2,3,6}$ Rainbow IVF, Agra, Uttar Pradesh, India

${ }^{4}$ Department of Obstetrics and Gynecology, Sarojini Naidu Medical College, Agra, Uttar Pradesh, India

${ }^{5}$ Department of Obstetrics and Gynecology, Ashwini Maternity \& Surgical Hospital, Mumbai, Maharashtra, India

Corresponding Author: Niranjan Shah, Consultant, Department of Obstetrics and Gynecology, Lotus Hospital \& Research Centre Kolhapur, Maharashtra, India, e-mail: doc1a1@yahoo.com
}

delivery, fear of morbidity and mortality, long-term effects of difficult vaginal delivery on mother and fetus, drop in maternal mortality and morbidity over the years, changes in technique and safety in cesarean, etc., must be considered along with the precarious condition of the medical field, with the legal liabilities and violence and morbidity and mortality accusations heaped on the medical profession in an inadvertent incidence.

It is definitely not only the monetary reason as is being pointed out to be the sole cause for the rise in cesarean rates, and neither is it appropriate to blame only the medical community for the same.

\section{THE WHO STATEMENT ON CESAREAN SECTION RATES}

\section{Cesarean Section Rates at the Population Level}

The World Health Organization (WHO) conducted two studies: a systematic review of available studies that had sought to find the ideal cesarean rate within a given country or population, and a worldwide countrylevel analysis using the latest available data. Based on these available data, and using internationally accepted methods to assess the evidence with the most appropriate analytical techniques, the WHO concludes:

- CSs are effective in saving maternal and infant lives, but only when they are required for medically indicated reasons.

- At a population level, CS rates higher than $10 \%$ are not associated with reductions in maternal and newborn mortality rates. (This has been subsequently challenged by the Ariadne labs study in the journal N Engl J Med.)

- CSs can cause significant and sometimes permanent complications, disability, or death, particularly, in settings that lack the facilities and/or capacity to properly conduct safe surgery and treat surgical complications. Cesarean sections should ideally only be undertaken when medically necessary.

- Every effort should be made to provide CSs to women in need, rather than strive to achieve a specific rate.

- The effects of CS rates on other outcomes, such as maternal and perinatal morbidity, pediatric outcomes, and psychological or social wellbeing are still unclear. More research is needed to understand the health effects of CS on immediate and future outcomes. 
CS RATES AT THE HOSPITAL LEVEL AND NEED FOR A UNIVERSAL CLASSIFICATION SYSTEM

There is currently no internationally accepted classification system for CS that would allow meaningful and relevant comparisons of CS rates across different facilities, cities, or regions $(\mathrm{WHO} / \mathrm{RHR} / 15.02 \odot$ World Health Organization 2015).

Among the existing systems used to classify CSs, the 10-group classification (also known as the "Robson classification") has in recent years become widely used in many countries. In 2014, the WHO conducted a systematic review of the experience of users with the Robson classification to assess the pros and cons of its adoption, implementation, and interpretation, and to identify barriers, facilitators, and potential adaptations or modifications. The WHO proposes the Robson classification system as a global standard for assessing, monitoring, and comparing CS rates within health care facilities over time, and between facilities. In order to assist health care facilities in adopting the Robson classification, the WHO will develop guidelines for its use, implementation, and interpretation, including standardization of terms and definitions.

\section{CESAREAN RATES AND THE CONFUSION THAT SURROUNDS THEM}

There is a surprising lack of clarity among various organizations on cesarean rates. It is altogether surprising that rhetoric has replaced - sometimes even dangerously — what is best for the woman, her baby, and the family. We believe that a rational evidence-based approach to this issue is vital rather than the lazy narrative of the commercialization of medicine, in general, and birthing in particular.

The current rates in various countries are mentioned in Figure 1. Data for each country is from most recent

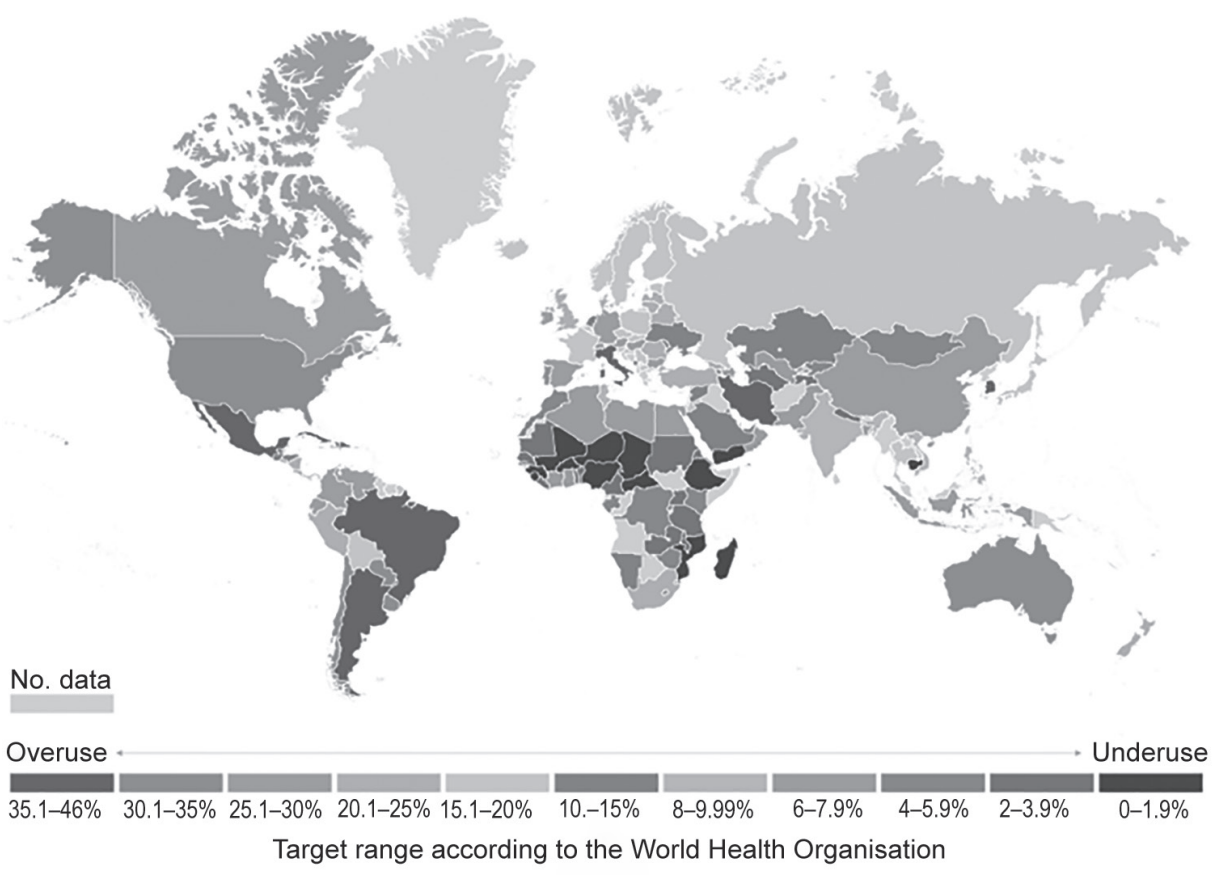

Source: World Health Organization

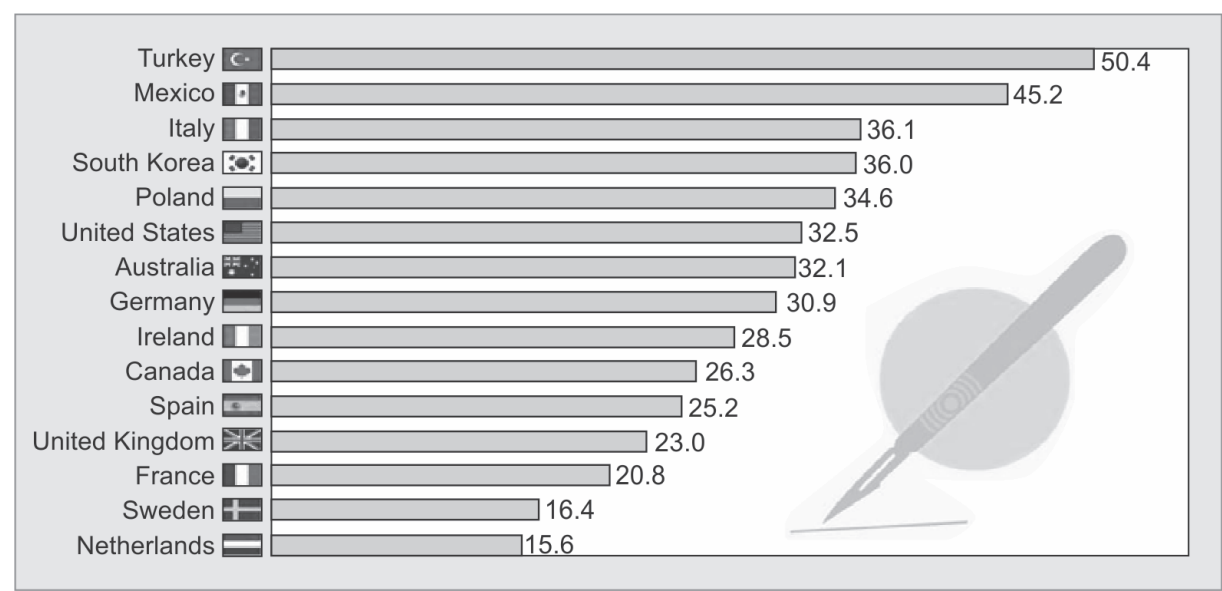

Source: OECD; Cesarean rate per 100 live births is selected OECD countries*

Fig. 1: Cesarean section rates in various countries 
year available. The Atlantic calls Brazil's high C-section rate-82 percent in the country's private hospitals-an "epidemic," driven in part by doctors that push interventions like labor-inducing drugs and painful episiotomies that can make $\mathrm{C}$-sections feel like a welcome alternative. But Brazil is not the only place in the world where the rates are too high, while elsewhere in the world access to $\mathrm{C}$-sections is woefully scant.

The question which begs to be answered is, therefore:

"Is there a recommended rate for CS?"

The short answer is NO.

However, confusion abounds in this aspect and it is worthwhile to take some time to understand the genesis of the canard of 10 to $15 \%$ cesarean rates.

In 1985, the WHO stated: "There is no justification for any region to have CS rates higher than $10-15 \%{ }^{\prime \prime}{ }^{1}$

The studies on which the WHO based the $15 \%$ recommendation 30 years ago were "limited by either having incomplete data or relying on averaged cesarean delivery rates from multiple years without accounting for year-toyear variation in these estimates". ${ }^{2}$ Although the methodology of arriving at these rates was not robust - to say the least-and the methodology has come under scrutiny in several publications, ${ }^{3}$ this document has provided fodder to several studies, which based the utility of CSs using these figures as a basic assumption.

What is almost always overlooked is that the WHO document looked upon reflected a correlation only with mortality. The rates were never meant to assess cesarean rates at the level of an individual facility or individual physician or patient. These rates were an indicator of accessibility, availability, and utilization of this facility, and are of use to policymakers as an indicator of maternal/perinatal health. ${ }^{4}$

Morbidity, both fetal and maternal, was not taken into account for these rates. This was and is an infirmity, which has not been addressed even now, adequately, to arrive at a uniform cesarean rate. It is also true that what are not considered are the longer term effects of birth on women; in particular, pelvic organ prolapse, anal sphincter injury, sexual dysfunction, fistulae, urinary incontinence, and others.

It is, therefore, not surprising to see data where the 10 to $15 \%$ cesarean rate has been found repeatedly wanting. None of the countries with a stillbirth rate of 2 to $4 / 1,000$ have a CS at the rates between the World Health Organisation's recommended 10 to $15 \%$ threshold. ${ }^{5}$

An elegant report cites that previously recommended national target rates for cesarean deliveries may be too low. The same report goes on to say that the focus of discussion about CS rates should be on "supporting safe and appropriate provision of cesarean delivery with the intent of reducing maternal and neonatal mortality without causing overuse of procedures". ${ }^{2}$ However, it was also clear that there is a "complex interplay between overall maternal health resources, emergency obstetrical services, and other factors".

Not surprisingly, the WHO issued a new statement in 2015 with the headline "Every effort should be made to provide caesarean sections to women in need, rather than striving to achieve a specific rate" ${ }^{\prime 6}$

A very recent commentary from the authors involved in the WHO statements notes that mortality is normally the only outcome considered in the analyses. Maternal and newborn morbidity (e.g., obstetric fistula, birth asphyxia), or psychological and social well-being (e.g., maternalinfant relationship, women's psychological health or ability to successfully initiate breastfeeding) as well as long-term pediatric outcomes should be considered when estimating a rate that would achieve optimal outcomes. However, since there are practically no morbidity data at the population level, it has not been possible to assess the ecological relationship between CS and these other outcomes. The Statement also consolidates the shift in the focus of attention from the search for an optimal CS rate that provides little basis for action, to a practical and feasible proposal: the use of the classification as a standard system to monitor and compare CS rates at the facility or other levels. ${ }^{7}$

Thus, to conclude, the current studies and recommendations have two fallacies, one of trying to extrapolate population level data to facility level and focusing on mortality with the exclusion of morbidity, either neonatal or maternal.

\section{INDIAN DATA}

As per the latest data (National Family Health Survey 2015-16, NFHS-4), the cesarean rates at the population level in India seem to be $17.2 \%$. The same document goes on to look at cesarean rates in the private and public sectors and while the discrepancy in the rates in these two sectors has been commented upon, there is no mention in the commentaries of the fact that the private sector delivers more babies than the public sector in the urban sector and with absolutely no indication of morbidity rates either maternal or neonatal in either sector.

There is also no acknowledgment of the fact that the lower rates in public sector could simply be a reflection of the paucity of capacity, both infrastructure and human resource.

The CS rate limits used to define underuse and overuse may be a matter for discussion since any classification has some constraints. The $15 \%$ upper limit suggested by the WHO in 1985 could be less valid nowadays, taking into account changes of the population in high-income countries, such as mother's age at the first 
child, birthweight, and other factors, which may result in needing more or less CS. ${ }^{8}$

To reiterate, a quote from the $\mathrm{WHO}$ working group on cesarean section says, "The time has come to put the debate about the preferable rate of CS on hold. Let's start to collect data uniformly so that in the near future we will be able to move our focus from CS rates at population level to monitoring and discussing CS rates and outcomes in each group of the Robson classification. Only then will we have the data and evidence that will lead us more clearly to actions to improve care". ${ }^{3}$

The Federation of Gynaecological Societies of India recommends the setting up of a cloud-based registry linked to its website, which will collect anonymous data at the hospital level using the WHO recommended Robson's ten-group classification system.

We would like to emphasize that the hallmark of labor management in the 21st century should be individualized care for the laboring woman with the expectation of a successful and safe vaginal delivery, together with the ability to intervene with a cesarean delivery, if needed, to prevent morbidity and mortality.

\section{THE NGO/ADVOCACY GROUP'S APPARENT PERSPECTIVE}

Recent data from the National Family Health Survey 2014-15 (NFHS-4) reveals that at the all-India level, the rates of CSs have doubled over the last decade, while in last 20 years, it has risen six times. In some states like Telangana, Tripura, West Bengal, Kerala, Goa, Andhra Pradesh, and Tamil Nadu, the rate is alarmingly high, with Telangana $(74.9 \%)$ having the highest number of CS deliveries in private hospitals. There is no denying that CSs can be a life-saving procedure for child delivery and might be absolutely unavoidable in some cases. However, the increasing influence of nonmedical factors for performing CSs is a growing concern. ${ }^{10}$

Data show that the cesarean rates are three times higher in private hospitals (31.1\%) as compared with public hospitals $(10.0 \%)$. This may be a reflection of increasing privatization, betraying a greater profit motive in the provision of health care facilities in recent times. On analyzing deliveries by wealth index (2005-06) for Indian women from richer families, the CS rate is almost $26 \%$, while for the poorest women, it is only $1.5 \%$. It can be the result of a better access to the upper class and not so to the lower, suggesting paucity of capacity in infrastructure and human resource in the public sector (Table 1).

\section{SCIENCE OR COMMERCE OF MEDICINE (ANOTHER ALLEGATION)}

The fact that CS rates are higher in the private sector as compared with public hospitals is clearly linked with the
Table 1: Births delivered by CS

\begin{tabular}{llllll}
\hline \multirow{2}{*}{$\begin{array}{l}\text { Births delivered } \\
\text { by CS (\%) }\end{array}$} & \multicolumn{3}{c}{ NFHS-4 (2014-15) } & & \multicolumn{2}{c}{$\begin{array}{c}\text { NFHS-3 } \\
\text { (2005-2006) }\end{array}$} \\
\cline { 2 - 4 } \cline { 2 - 3 } All India & Urban & Rural & Total & & Total \\
Maharashtra & 20.1 & 20.1 & 20.1 & 11.6 \\
Bihar & 63.2 & 53.4 & 58 & \\
Haryana & 48.4 & 37.1 & 40.1 & - \\
Tripura & 45.8 & 12.2 & 20.5 & 12.9 \\
Tamil Nadu & 36.1 & 32.3 & 34.1 & 20.3 \\
Andhra Pradesh & 33.5 & 27.7 & 31.4 & 25.7 \\
Gujarat & 29.2 & 19.9 & 23.6 & 15.5 \\
Goa & 27.8 & 12 & 18.4 & 8.9 \\
Telangana & 26.3 & 15.2 & 20.1 & 11.6 \\
Kerala & 13.9 & 5.4 & 6.2 & 3.1 \\
\hline
\end{tabular}

Source: NFHS-4, NFHS-3

profit motive. Another very important cause is "doctorinduced demand." Obstetricians push for CSs as it fetches a higher income for the doctor and the hospital. Besides, doctors are seen with reverence and one prefers not to go against their word. Often, doctors misuse this trust and play on the fear that women might have about a normal delivery. Wrong counseling/government medical colleges using patients as training scapegoats and doctors from private medical colleges without experience in taking a call on mode of delivery lead in excess number of cesareans.

It is often argued that women should choose the type of the delivery they want. Here, the doctor's role is very crucial in informing women about the pros and cons of having a CS. However, in reality, this freedom is being encashed upon by doctors. Further, it has also been observed that in the hospitals affiliated to medical colleges, generally the rates of CSs are higher, since the resident doctors feel that they need practice to gain expertise in surgical skills. What is even more worrisome is that now, many doctors, especially those graduating from private medical collages, have very little experience in conducting normal deliveries. If labor is prolonged, they are quick to jump to a CS.

\section{PATIENT DEMANDS}

Reasons for "demand for cesarean":

1. Fear due to self-capacity/morbidity/mortality

a. Birth experience-pain/previous adverse birth experience

b. Potential maternal consequences-pelvic organ prolapse/sexual problems/urinary and anal problems.

c. Potential fetal consequences-complications in birth process/injury/mortality. ${ }^{11}$

In deliveries that did not involve fetal distress, severe complications for the baby were $80 \%$ 
higher following midpelvic forceps and midpelvic vacuum compared with cesarean delivery. The rate of severe birth trauma was five- to tenfold higher in deliveries by midpelvic forceps and midpelvic vacuum compared with cesarean delivery. Severe obstetric tearing occurred in 19\% of women delivered by midpelvic forceps, $12 \%$ of women delivered by midpelvic vacuum, and $20 \%$ of women that delivered using a combination of midpelvic vacuum and forceps.

2. Social status

3. Religious and personal whims

4. Not known.

\section{OBSTETRICIAN PERSPECTIVE (GENERAL CONSENSUS)}

\section{Reasons for Practice Changes}

- Medical reasons/cascading interventions/induction/ CFM/ARM/epidural, etc.

- Physician-driven factor

- Advancement in technology

- CPA/Legality

- Ability

- Violence/physical and hospital damage

- Cesarean delivery on maternal request

- Monetary.

\section{Biggest Threat: Violence}

Unprecedented rise in violent incidences by following threats:

- Psychological

- Physical

- Property.

Result: Disregard to guidelines, laws, ethics, and statistics. Goal: Safe mother and baby by any route of delivery

The truth lies somewhere in these two:

"Birth is a disaster waiting to happen, Birth is not a disaster waiting to happen!"

\section{Interventions}

\section{Mothers}

- Address psychological maternal needs

- Dispel fear around birthing experience

- Education on risks and benefits of CS

- Communication channels between all stakeholders.

\section{Obstetricians}

- Abide by ethics/indication/unbiased decision before performing CS on demand/request.
- Debate will continue.

- Discussion of risks and benefits is a must.

\section{Strategy by Professional Bodies}

- Proper data collection/research trends

- Relationship with other variables

- Reasonable assessment of women's requests

- Interventions in the form of public education

- Training of future obstetricians

- Standardization of the definition of cesarean on demand

- A checkbox for maternal request on birth certificate.

- Strengthen Doctor Protection Act.

\section{Prime Intervention by Professional Bodies}

- Vigilance over laws on security issues pertaining to doctors

- Focused leadership of official organizations to protect doctors

- Assurance of protection to the medical practitioner against violence and threat to life.

\section{CONCLUSION}

The scientific, public health, and medical community have raised concerns about this supposed global epidemic, while the search for ideas and interventions to reduce CS is ongoing. However, the rational and responsible reduction of CS is not a trivial task, and it will take considerable time and efforts. Monitoring both CS rates and outcomes is essential to ensure that the policies, practices, and actions targeting the optimal use of CS leads to improved maternal and infant outcomes.

A broad sense balance for an optimal CS rate will need an approach as defined below:

Amiddle ground should be between the two approaches to birth (patients' perspective) and risk (both patients' and doctors' perspective) - between vigilance toward the disaster waiting to happen and not a disaster waiting to happen.

So surgery happens when necessary, but is avoided in the many cases when it's not.

\section{REFERENCES}

1. World Health Organization. Appropriate technology for birth. Lancet 1985 Aug;2(8452):436-437.

2. Molina G, Weiser TG, Lipsitz SR, Esquivel MM, Uribe-Leitz T, Azad T, Shah N, Semrau K, Berry WR, Gawande AA, et al. Relationship between cesarean delivery rate and maternal and neonatal mortality. JAMA 2015 Dec;314(21):2263-2270.

3. Betran AP, Torloni MR, Zhang JJ, Gülmezoglu AM; for the WHO Working Group on Caesarean Section. WHO statement on caesarean section rates. BJOG 2016 Apr;123(5):667-670.

4. Betran AP, Merialdi M, Lauer JA, Bing-Shun W, Thomas J, Van Look P, Wagner M. Rates of caesarean section: analysis 
of global, regional and national estimates. Pediatr Perinatal Epidemiol 2007 Mar;21(2):98-113.

5. Leddy MA, Power ML, Schulkin J. The impact of maternal obesity on maternal and fetal health. Rev Obstet Gynecol 2008 Fall;1(4):170-178.

6. World Health Organization. WHO statement on caesarean section rates. Geneva: World Health Organization; 2015 (WHO/RHR/15.02).

7. Betrán AP, Zhang J, Torloni MR, Gülmezoglu AM. Determination of a single, universal threshold for caesarean section rate is not the way forward. Evid Based Med 2016 Dec;21(6):237.

8. Gibbons L, Belizán JM, Lauer JA, Betrán AP, Merialdi M, Althabe F. The global numbers and costs of additionally needed and unnecessary caesarean sections performed per year: overuse as a barrier to universal coverage. World Health Report working paper; 2010.

9. Caughey AB. Can we safely reduce primary cesareans with greater patience? Birth 2014 Sep;41(3):217-219.

10. Marathe S, Mukadam R. Profiteering hospitals are driving alarming rise in C-section deliveries in India [cited 2017, April 21]. Available from: https://thewire.in/125725/ c-sections-health-women-pregnancy/

11. Cesarean deliveries better than midpelvic forceps, vacuum deliveries: (Canadian Medical Association Journal). Read more at Medical dialogues: cesarean deliveries better than midpelvic forceps, vacuum deliveries: study. Retrieved from http:/ / speciality.medicaldialogues.in/cesarean-deliveriesbetter-than-midpelvic-forceps-vacuum-deliveries-study / 